\title{
Ciência e teatro: um estudo sobre as artes cênicas como estratégia de educação e divulgação da ciência em museus
}

\author{
Science and theater: a study of the performing Arts \\ as a strategy for Science communication in museums
}

\author{
Carla da Silva Almeida ${ }^{1}$. Maíra Freire ${ }^{2}$. Luiz Bento ${ }^{2}$. \\ Gabriela Jardim $^{2}$. Marina Ramalho ${ }^{1}$. Monica Dahmouche ${ }^{2}$
}

\begin{abstract}
Resumo: $\mathrm{O}$ teatro tem sido usado como estratégia de educação e divulgação da ciência em museus. Neste artigo, analisamos duas atividades teatrais oferecidas pelo Museu Ciência e Vida, de Duque de Caxias (RJ). Com base em entrevistas e questionários, verificamos que os visitantes consultados têm familiaridade com o teatro, embora sejam frequentadores esporádicos desses espaços. Aqueles com menos acesso a programas culturais, envolvimento prévio com as temáticas abordadas e cujos filhos se engajaram na atividade tenderam a uma recepção positiva da mesma. Quando a atividade não atraía a criança ou a expectativa em relação a ela era diferente da vivenciada, a tendência foi de insatisfação. Independentemente das opiniões colhidas, vimos que as atividades despertaram no público reações que seriam dificilmente provocadas por atividades tradicionais do museu. Por este e outros motivos, defendemos a interação entre ciência e teatro como uma estratégia instigante e diferenciada de educação e divulgação da ciência.
\end{abstract}

Palavras-chave: Ciência e teatro. Museu de ciência. Divulgação científica. Educação científica.

\begin{abstract}
Theater has been used as a strategy for science education and communication in museums. In this article, we analyze two theatrical activities offered by the Museum of Science and Life, located at Duque de Caxias (RJ). Based on interviews and questionnaires, we found that the visitors consulted are familiar with the theater, although they are not frequent visitors. Those with less access to cultural programs, previous involvement with the topics addressed and whose children engaged in the activity tended to receive it positively. When the activity did not attract the child in the group or the expectation it raised was different from that expected, the tendency was dissatisfaction. Regardless of the opinions gathered, we observed that the activities aroused public reactions that would be difficult to provoke by traditional museum activities. Thus, we advocate the interaction between science and theater as a differentiated strategy for science education and communication.
\end{abstract}

Keywords: Science and theater. Science museum. Science communication. Science education.

\footnotetext{
${ }^{1}$ Fundação Oswaldo Cruz, Museu da Vida, Rio de Janeiro, RJ, Brasil. E-mail: <carla.almeida@fiocruz.br>.

${ }^{2}$ Fundação Centro de Ciências e Educação Superior a Distância do Estado do Rio de Janeiro, Museu Ciência e Vida, Rio de Janeiro, RJ, Brasil.
} 
Almeida, C. S.; Freire, M.; Bento, L.; Jardim, G.; Ramalho, M.; Dahmouche, M.

\section{Introdução}

A interface entre ciência e arte não é assunto recente, mas a partir da publicação de $A s$ duas culturas, de C. P. Snow, em 1959, o debate ganhou mais interesse e atenção (MASSARANI; MOREIRA; ALMEIDA, 2006). Desde que o físico e romancista inglês criticou, na famosa obra, a separação entre as ciências naturais e as humanidades, vários pensadores vêm se dedicando à reflexão e ao estudo das interações, convergências e divergências entre essas duas formas de interpretar o mundo. É possível identificar na literatura acadêmica tanto reflexões sobre a interface entre ciência e arte de maneira mais geral, quanto estudos sobre suas interseções em ramos artísticos específicos, desde as artes plásticas até o cinema, incluindo também a literatura, o teatro e a música (HISTÓRIA, CIÊNCIAS, SAÚDE-MANGUINHOS, 2006). Pode-se verificar nessa literatura diversas maneiras de abordar o tema, cada uma delas apontando para direções e objetivos distintos.

Neste trabalho, nosso interesse é a interseção entre ciência e teatro, uma forma de arte que, por sua natureza, engloba várias outras, como a literatura, a música e as artes plásticas (LOPES, 2005). Estamos interessados mais especificamente em compreender se e como a linguagem e os recursos teatrais podem se aliar à educação e divulgação da ciência em seus esforços de aproximação entre ciência e sociedade.

O teatro, com seus cenários, luzes e figurinos, de um lado, e palavras, ideias e pensamentos, do outro, oferece uma forma muito particular de ver e refletir sobre o mundo, a partir da mobilização de sentidos e emoções (FRUGUGLIETTI, 2009). Não à toa, as artes cênicas vêm sendo cada vez mais exploradas em iniciativas de ensino de ciências (ver MEDINA; BRAGA, 2010; MESSEDER NETO; PINHEIRO; ROQUE, 2013) e de divulgação científica (MOREIRA; MARANDINO, 2015a, 2015b). Por meio do teatro tem sido possível abordar temas complexos da ciência de forma mais envolvente (BAUM; HUGHES, 2001; BLACK; GOLDOWSKY, 1999; RICHARDS, 2008). O teatro também tem permitido tratar aspectos da ciência pouco abordados em atividades tradicionais de divulgação, como seu lado controverso, ético e político, bem como tem possibilitado explorar o lado mais humano dos cientistas, com seus dilemas e conflitos pessoais (MOREIRA; MARANDINO, 2015a, 2015b), raramente expostos ao público. Desta forma, e ao transformar o registro de dados objetivos da ciência em situações emocionantes, o teatro pode ser ainda uma maneira de desconstruir a suposta frieza da atividade científica e aproximá-la do público (LOPES, 2005).

Por outro lado, tais aspectos da atividade científica e da vida dos cientistas são um prato cheio para o drama. Assim, o teatro também tem aberto as cortinas para temas científicos. Em alguns países, sobretudo na Europa, o teatro com mote científico que já está incorporado à agenda cultural da sociedade, com peças de grande sucesso de crítica e público como Vida de Galileu, de Bertolt Brecht; Copenhagen, de Michael Frayn; Arcadia, de Tom Stoppard; Einstein, de Gabriel Emanuel; e Oppenheimer, de Tom Morton-Smith (SHEPHERD-BARR, 2006). Tais peças, escritas em sua maioria por renomados dramaturgos, não pretendem ensinar ou divulgar ciência; elas se apoiam no prazer e na sensibilidade dos espectadores para refletir sobre a natureza humana e o sentido da vida e do mundo (MOREIRA; MARANDINO, 2015a).

Independentemente dos fins, o fato é que há um crescimento das interações entre ciência e teatro, especialmente nos Estados Unidos e na Europa, mas também na América 
Latina e no Brasil, e parte importante dessas interações têm ocorrido em museus e centros de ciência. Essas instituições têm desempenhado papel preponderante na educação não formal e na popularização da ciência, sobretudo nas últimas três décadas, sendo locais privilegiados de aproximação entre ciência, educação, cultura e sociedade; de socialização do conhecimento científico; e de encontro de saberes. Ao mesmo tempo, enfrentam o desafio permanente de oferecer aos visitantes uma programação dinâmica e sintonizada com as transformações sociais, no intuito de cumprir sua missão educativa e cultural. Assim, estão sempre em busca de novas estratégias e linguagens e o teatro com temática científica desponta nesse contexto (MOREIRA; MARANDINO, 2015a).

Em alguns museus de ciência norte-americanos e europeus, peças com motes científicos já estão incorporadas à programação, como nos museus de ciência de Boston (BAUM; HUGHES, 2001) e de Minnesota (COHN, 2010), nos Estados Unidos, e no Museu de Ciência de Londres, no Reino Unido (RICHARDS, 2008), que investe também em intervenções dramatizadas nas salas de exposição. Mais recentemente e de forma mais ou menos assídua, alguns museus de ciência brasileiros incluíram peças ou recursos teatrais em sua programação, como: Museu da Vida (RJ), Casa da Ciência (RJ), Catavento Cultural e Educacional (SP), Espaço do Conhecimento (MG), Museu de Astronomia e Ciências Afins (RJ), Seara da Ciência (CE) e Museu de Artes e Ofícios (MG) (GUSMÃO et al., 2012; MOREIRA, 2013; MOREIRA; MARANDINO, 2015a, 2015b).

Se, de um lado, as iniciativas unindo ciência e teatro são cada vez mais numerosas, de outro, a literatura sobre elas ainda é escassa e, em grande medida, estrangeira. Temos poucos dados sobre como as atividades brasileiras do gênero ocorrem, com que frequência, onde se concentram, quais os atores envolvidos, quem os apoia e, sobretudo, com que resultados. Em esforço recente de mapeamento da interface entre ciência e teatro em centros e museus de ciência brasileiros, Moreira e Marandino (2015a, 2015b) observaram que a maioria das iniciativas tem um viés didático, voltando-se para o ensino e a divulgação da ciência, e é realizada por pessoas sem formação em artes cênicas. No que se refere à periodicidade, há ações permanentes e eventuais, sendo as eventuais mais frequentes. Os autores constataram ainda uma forte associação entre os temas das atividades teatrais e das exposições em cartaz nos museus de ciências, sendo as últimas muitas vezes responsáveis por determinar os assuntos das primeiras.

Para compreender melhor as diversas facetas do uso do teatro como estratégia de educação e divulgação da ciência e avaliar a pertinência de investimento de recursos em ações que as unem, os autores do presente artigo iniciaram um projeto voltado ao estudo das interações entre ciência e artes cênicas. Neste primeiro trabalho no âmbito do projeto, analisamos duas atividades teatrais promovidas pelo Museu Ciência e Vida, localizado em Duque de Caxias, no Rio de Janeiro. Combinando diferentes metodologias, que serão descritas ao longo do artigo, buscamos responder às seguintes perguntas:

- quais os perfis e hábitos culturais dos participantes das atividades?;

- como receberam as novas experiências teatrais oferecidas pelo Museu Ciência e Vida?;

- qual o potencial do teatro como estratégia de divulgação científica no Museu Ciência e Vida e em museus e centros de ciência em geral? 


\section{Referencial teórico}

Como o campo da divulgação científica ainda carece de uma teoria consolidada para estudar as interseções entre ciência e teatro, buscamos referenciais teóricos de outras áreas para embasar nossas pesquisas. Para este estudo específico, nos fundamentamos particularmente no conceito de capital cultural presente na obra do sociológico francês Pierre Bourdieu, amplamente disseminado no campo da pesquisa em museus.

Os conceitos de capital social e cultural começaram a ser desenvolvidos por Bourdieu na década de 1960, no contexto de pesquisas sobre desempenho escolar. Ao se debruçar sobre o tema, o sociólogo mostrou que ser bom aluno não depende apenas de boa vontade e menos ainda resulta de um dom individual inato voltado aos estudos, o desempenho escolar estaria fortemente associado à origem social dos alunos. Dentre os fatores relativos a essa "origem social", dados empíricos levantados por Bourdieu e outros autores logo revelaram que as condições financeiras eram insuficientes para explicar as diferenças de performance entre os alunos e que outros fatores sociais e culturais contribuíam igualmente para fortalecer a relação entre nível socioeconômico e resultados escolares. Esta visão entrava em choque com a ideia vigente de que o sistema educacional massivo oferecia a todos as mesmas chances (CAZELLI, 2005; NOGUEIRA; NOGUEIRA, 2002).

Para os fins deste trabalho, nos interessa particularmente a acepção de capital cultural conforme apresentada por Bourdieu (2001b). De acordo com o sociólogo, o capital cultural existe em três estados: incorporado, objetivado e institucionalizado. No estado incorporado, o capital cultural está relacionado ao gosto, ao domínio de códigos e linguagens e aos conhecimentos teóricos necessários para desenvolver o gosto e decifrar os códigos que permitem o acesso à cultura. A incorporação desse capital é lenta e resulta de um trabalho de inculcação e assimilação. Nesse sentido, um meio familiar favorável, marcado por ricas referências culturais, conhecimentos considerados apropriados e legítimos e o domínio da língua culta, é essencial para a aquisição de capital cultural. Já no estado objetivado, o capital cultural existe sob a forma de bens culturais, tais como livros, pinturas, entre outros objetos de valor artístico-cultural. Para apropriar-se de fato desses bens, é necessário mais do que capital econômico; é preciso possuir capital cultural no estado incorporado. Por fim, no estado institucionalizado, o capital cultural materializa-se por meio dos diplomas e títulos (CAZELLI, 2005; BOURDIEU, 2001b).

Bourdieu mostrou ainda uma associação forte entre a posse de capital cultural e a apropriação da arte, em especial das artes plásticas eruditas, mas também das artes cênicas e de outras expressões artísticas. Em estudo meticuloso sobre o público de museus de arte e centros culturais da Europa conduzido com Darbel nos anos 1964 e 1965 (BOURDIEU; DARBEL, 2007), o sociólogo identificou uma correlação entre o grau de instrução e a frequência a esse tipo de equipamento cultural. As evidências colhidas revelaram o peso do capital cultural, em seus diversos níveis, para o devido usufruto dos bens culturais que, a princípio, estariam disponíveis a todos - assim como a educação básica -, mas que, na verdade, exigem pré-requisitos mínimos e um meticuloso trabalho de inculcação para se tornarem acessíveis de fato (BOURDIEU; DARBEL, 2007). Tais evidências fortalecem o argumento de Bourdieu de que capital cultural gera capital cultural. E, por não subverterem essa lógica, reforçando teorias sobre dons inatos, boa vontade e prazer estético e o discurso sobre a suposta universalidade de acesso, museus de arte e centros culturais perpetuariam as desigualdades sociais. 
Nosso trabalho também se embasa em alguns pontos de convergência entre as reflexões propostas pelos estudos culturais de audiência ingleses e os estudos de recepção latino-americanos, ambos pertencentes ao campo da comunicação. Segundo a corrente dos estudos culturais, no processo de transmissão de mensagens há sempre uma negociação de sentido por parte dos receptores, com base em seus repertórios culturais. As mensagens são polissêmicas e o sentido não é uma propriedade inerente ao meio ou aos textos isoladamente; eles são gerados a partir de uma negociação entre o discurso produzido a partir de um determinado código e as decodificações que as audiências realizam mobilizando seu capital cultural (WOLF, 2003). Em consonância com tais premissas estão os estudos de recepção latino-americanos. Nesse campo, argumenta-se que os receptores de uma mensagem estão expostos constantemente a mediações variadas - como a relação com a família, com a escola e seu contexto sociocultural - que interferem na construção de sentidos diferenciados (MARTÍN-BARBERO, 1987). Logo, receptores são atores ativos da comunicação e a mesma mensagem pode gerar interpretações diferentes para receptores distintos.

Em síntese, este trabalho, em consonância com a corrente atual de estudos de visitantes (visitor studies), coloca o receptor no foco das investigações (HOOPER-GREENHILL, 2006), considerando suas origens e condições socioculturais, além das mediações a que estão expostos em seu cotidiano, como referenciais importantes para a experiência que terão no museu, particularmente em atividades teatrais.

\section{Procedimentos metodológicos}

O Museu Ciência e Vida é um centro interativo de ciências localizado em Duque de Caxias, na Baixada Fluminense, região com um dos índices sociais e educacionais mais baixos do estado do Rio de Janeiro e carente de equipamentos culturais e opções de lazer em geral. Aberto ao público em julho de 2010, o museu, que integra o programa de divulgação científica da Fundação Centro de Ciências e Educação Superior a Distância do Estado do Rio de Janeiro (CECIERJ), é fruto de uma política pública voltada às necessidades locais, tendo sido pensado e planejado para suprir parte da falta de oferta cultural na região. Dentre as atividades do museu, destacam-se exposições, sessões de planetário, oficinas interativas e encontros com cientistas, voltadas ao público escolar e espontâneo. O museu ainda promove exibições de filmes e apresentações musicais, buscando se consolidar também como um espaço de lazer para os moradores da Baixada Fluminense. O museu recebe ao ano uma média de 35 mil visitantes, dos quais cerca de 60\% são frequentadores espontâneos que vão ao museu, sobretudo aos finais de semana.

Visando diversificar sua programação e oferecer uma nova opção de atividade cultural a seu público espontâneo, composto, sobretudo, por grupos familiares, o Museu Ciência e Vida promoveu no final de 2014 e início de 2015 duas atividades teatrais em seu espaço. Para uma delas, contratou a companhia Teatro Artesanal, que criou a peça Rossum e Asimov com contribuições da direção do museu. Essa companhia tem experiência em espetáculos para o público infantil e, apesar de nunca ter se apresentado em museus de ciências antes, já havia produzido uma peça sobre o físico Albert Einstein em outro projeto da Fundação Cecierj. A peça Rossum e Asimov se passa em um laboratório onde dois palhaços cientistas trabalham para o desenvolvimento tecnológico. Em meio a caixas coloridas, tubos de ensaio e ideias mirabolantes, Rossum tenta 
convencer Asimov de que está a um passo de uma grande descoberta. Já o atrapalhado Asimov acredita ter concebido maravilhosas engenhocas.

A outra experiência teatral do museu ocorreu em paralelo à peça Rossum e Asimov e possui características distintas. Fugindo ao formato tradicional das peças teatrais, encenadas em um palco dentro de um teatro (ou auditório, como em Rossum e Asimov), essa atividade ocorreu no espaço da exposição "A Herança da Terra: salvar o planeta do Pequeno Príncipe", que tratou da obra do autor francês Antoine de Saint-Exupéry, com o intuito de refletir sobre o destino do homem e da Terra. A apresentação, um monólogo, foi concebida pela companhia de teatro francesa Noir sur Blanc e encenada por um de seus atores no papel do escritor, que recitava trechos de seus livros e cartas e percorria e comentava os painéis da mostra. A companhia não possuía experiência prévia com ações de divulgação científica; seu trabalho, em geral, envolve espetáculos com temas voltados a cultura e língua francesas, com foco principalmente nos alunos da Aliança Francesa, realizadora da exposição "A Herança da Terra".

Para analisar as atividades mencionadas e buscar responder nossas perguntas de partida, conjugamos dois métodos de pesquisa, um quantitativo e outro qualitativo. A interface quantitativa da pesquisa compreendeu a aplicação de questionários fechados ao público espontâneo das duas atividades teatrais mencionadas. Estes incluíam tópicos sobre o perfil do visitante (sexo, idade, local de residência), hábitos culturais relacionados ao teatro e familiaridade com o Museu Ciência e Vida. Os dados colhidos foram tabulados e analisados com o auxílio do programa SPSS (Statistical Package for the Social Sciences). Os questionários foram respondidos por 131 pessoas, dos quais 76 correspondem à visita teatralizada à exposição "A Herança da Terra", realizada em 12 sessões, entre 13 de novembro de 2014 e 01 de fevereiro de 2015, da qual participaram cerca de 170 visitantes espontâneos. Os demais 55 questionários foram respondidos pelo público da peça Rossum e Asimov, que teve seis apresentações no museu entre 19 de outubro de 2014 e 31 de janeiro de 2015 com um número aproximado de 205 espectadores. Embora os questionários tenham sido distribuídos a todos os participantes, em todas as sessões de ambas as atividades, alguns responderam pelo grupo e outros preferiram não responder.

A parte qualitativa da pesquisa incluiu apenas o público da visita teatralizada e buscou compreender a recepção da atividade entre os participantes, além de aprofundar alguns dos tópicos abordados nos questionários. Foi elaborado para esta etapa um roteiro de entrevista semiestruturada, em que se buscou entender: quem é o visitante; qual a sua relação com o Museu Ciência e Vida; o contexto da visita e da participação na atividade; hábitos culturais e familiaridade com o teatro; recepção e percepções relacionadas especificamente à visita teatralizada; e a expectativa de retorno para atividades similares. Foram feitas 10 entrevistas com visitantes espontâneos selecionados aleatoriamente, logo após as apresentações. Todas as entrevistas foram gravadas e transcritas na íntegra e analisadas com base nos referenciais teóricos apresentados no item anterior. Mais especificamente, buscamos compreender as diferentes experiências proporcionadas pela atividade aos visitantes e identificar possíveis associações entre essas experiências, suas origens e condições socioculturais e as mediações que permeiam seu cotidiano. 


\section{Resultados}

\section{Questionários}

Considerando os dados dos dois questionários aplicados, verificamos que a mediana de idade dos respondentes foi 31,5 na visita teatralizada, e 37 na peça, o que coloca os dois casos dentro do intervalo de 30 a 39 anos utilizado em pesquisas do Observatório de Museus e Centros Culturais (OBSERVATÓRIO DE MUSEUS E CENTROS CULTURAIS, 2006). Em ambos os casos, o público respondente foi majoritariamente feminino, sendo $68 \%$ na visita teatralizada e chegando a $82 \%$ na peça. A maioria (51\%) morava em Duque de Caxias e uma parcela significativa $(17,5 \%)$ era residente do município do Rio de Janeiro, segunda cidade mais citada em termos de procedência dos visitantes consultados.

Quase todos os respondentes foram ao museu acompanhados, a maioria por familiares e amigos, e souberam das atividades principalmente via internet (30\% na visita teatralizada e $24 \%$ na peça) ou no próprio museu ( $29 \%$ na visita teatralizada e $53 \%$ na peça). De um terço, no caso da visita teatralizada, até metade dos respondentes, no caso da peça Rossum e Asimov, estava no Museu Ciência e Vida pela primeira vez. Dentre as justificativas apresentadas para não terem visitado o museu antes destacaram-se a falta de conhecimento sobre a existência do mesmo, a dificuldade de transporte e a falta de oportunidade (Gráfico 1).

Gráfico 1. Percentual das justificativas apresentadas pelos visitantes para nunca terem ido ao Museu Ciência e Vida antes da atividade

\section{Por que você nunca esteve no Museu Ciência e Vida?}
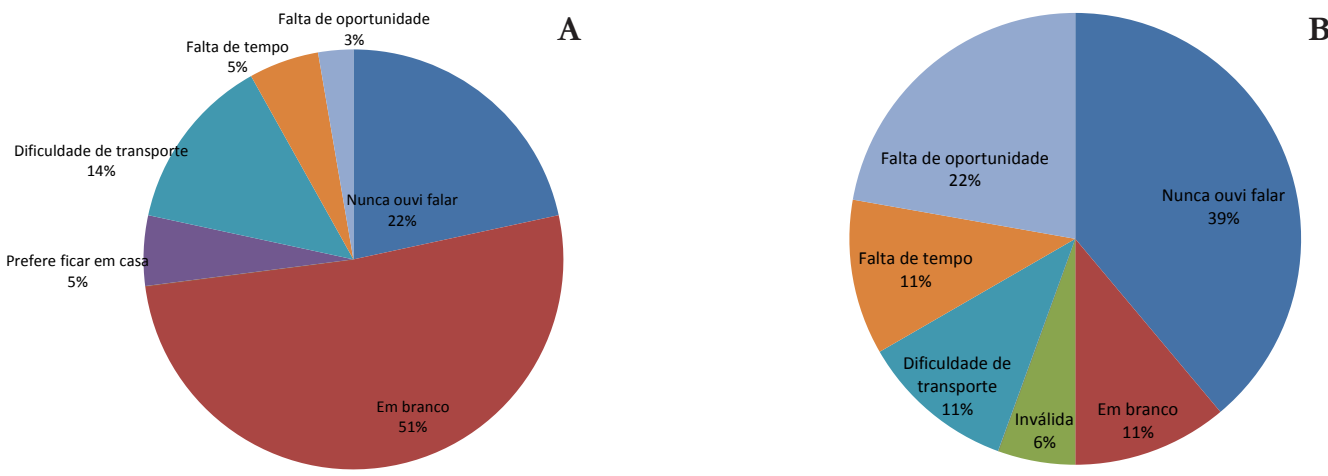

A: Respondentes que participaram da visita teatralizada $(\mathrm{n}=37)$. B: Respondentes que assistiram a Rossum e Asimov $(n=18)$.

Fonte: elaborado pelos autores a partir de dados da pesquisa.

A maior parte dos respondentes (84\%) que assistiram a Rossume Asimov já havia assistido a peças teatrais. No entanto, assim como observado nos questionários da visita teatralizada, 
assistir a espetáculos teatrais não desponta como um hábito frequente do público. Uma grande parcela dos respondentes não assistiu a peças de teatro no último ano ou só o fez de uma a três vezes nesse período. Entre as principais razões para a não aderência a esse tipo de programa foi a ausência de instituições que promovam o teatro perto de casa e questões financeiras (Gráfico 2). O Rio de Janeiro foi a cidade mais citada dentre os locais em que as peças de teatro foram vistas (16 vezes no questionário da peça e 24 no da visita teatralizada), mesmo a maior parte do público consultado sendo de Duque de Caxias (cerca de metade, em ambas as atividades).

Gráfico 2. Justificativas dos respondentes que declararam não ter assistido a nenhuma peça de teatro antes da visita ao Museu Ciência e Vida

\section{Por que você nunca havia assistido a uma peça de teatro?}
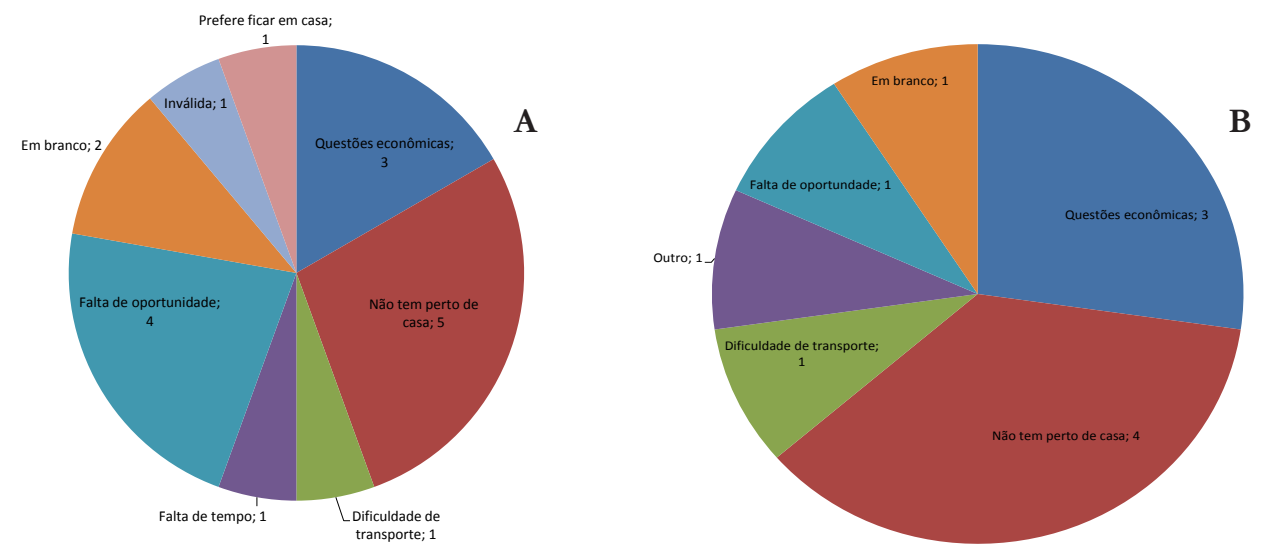

Os respondentes podiam citar mais de um motivo. A: Respostas dos participantes da visita teatralizada $(\mathrm{n}=18)$.

B: Respostas do público de Rossum e Asimov ( $\mathrm{n}=11)$.

Fonte: elaborado pelos autores a partir de dados da pesquisa.

A ciência como tema de peças de teatro parece ser novidade para o público consultado. Dos respondentes, menos de $20 \%$ (em ambas as iniciativas) afirmaram já ter visto peças com temática científica e só uma pequena parte destas foi capaz de lembrar alguma informação sobre a peça em questão. Entretanto, o interesse declarado de retornar ao museu e participar de atividades similares foi alto, tanto entre os respondentes que participaram da visita teatralizada quanto entre os que viram a peça Rossum e Asimov, variando de 96\% a 98\%, respectivamente (Gráfico 3). 
Gráfico 3. Interesse dos visitantes em participar de atividades similares no Museu Ciência e Vida
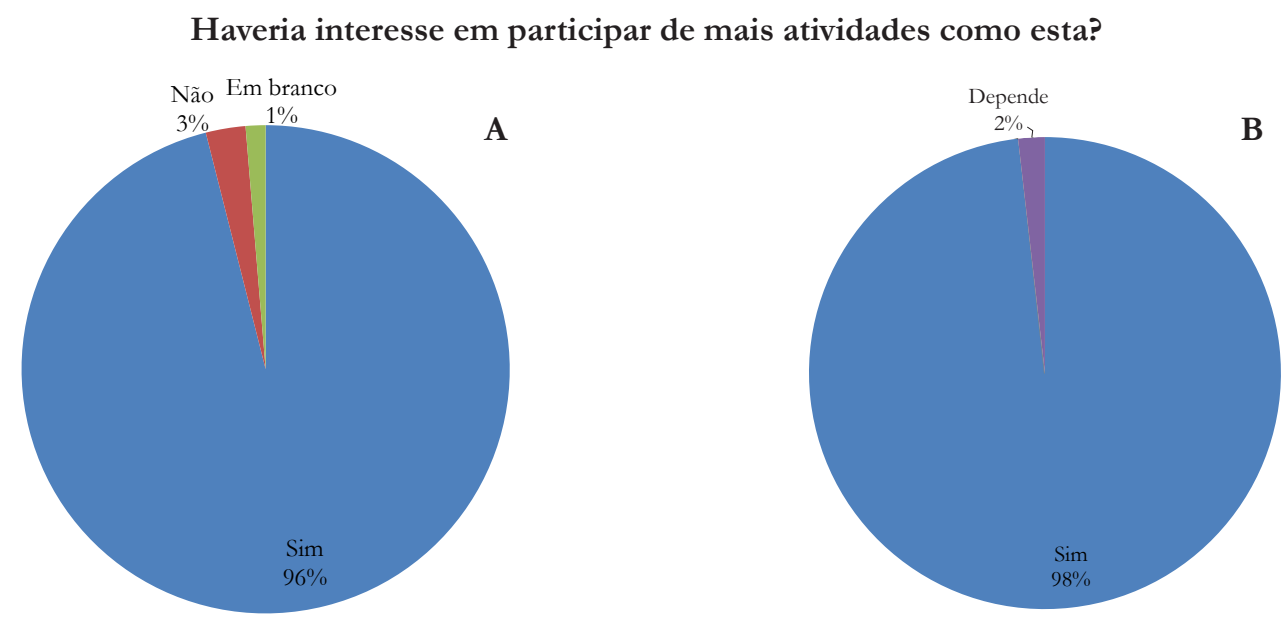

A: Percentual dos respondentes que participaram da visita teatralizada $(n=76)$. B: Percentual dos respondentes que assistiram a Rossum e Asimov ( $\mathrm{n}=55)$.

Fonte: elaborado pelos autores a partir de dados da pesquisa.

\section{Entrevistas}

\section{Perfil dos entrevistados}

Das dez entrevistas realizadas, oito foram individuais, sendo seis com mulheres e duas com homens. Das outras duas, uma foi realizada com quatro adolescentes mulheres e outra com um casal adulto (marido e esposa). A faixa etária dos entrevistados girou em torno de 30-39 anos, com exceção das adolescentes (de 15 e 16 anos) e de uma visitante de 48 anos. Todos eram moradores da Baixada Fluminense e apenas dois não eram de Duque de Caxias. Todos foram ao museu acompanhados de familiares, amigos, ou ambos. Os visitantes consultados relataram hábitos culturais diversos. A maioria disse pouco frequentar espaços culturais como museus e teatros, por razões diversas, que incluíam falta de oportunidade, de opções, de tempo ou mesmo de interesse. Entre esses visitantes, programas como ida a shopping center e ao cinema ou ficar em casa com a família eram mais comuns. Mas havia também, entre os entrevistados, frequentadores mais assíduos de espaços culturais. Entre estes, os programas mais citados foram passeios em espaços públicos, como a Quinta da Boa Vista, no Rio; visita a museus, como o CCBB, no Rio; e ida a teatros, como o Raul Cortez, em Duque de Caxias, e o Sesc Nova Iguaçu.

Independentemente da frequência com que participavam de atividades culturais, os grupos de visitantes demonstraram, em geral, uma valorização dessas atividades, vendo nelas uma oportunidade de enriquecer o conhecimento e a cultura e uma fonte importante de linguagens e conteúdo para a educação e formação dos filhos. Alguns falaram explicitamente que programas culturais, tais como visitas a museus, tornariam seus filhos pessoas melhores e mais inteligentes, como ilustra o trecho a seguir: 
Espontâneo 10a: É uma forma da gente ficarjunto, de educar, de participar, divulgar os conbecimentos, né? [...]

Entrevistadora: Ela costuma gostar quando faz esses passeios assim?

Espontâneo 10a: Sim.

Entrevistadora: O senhor acha que é importante pra ela?

Espontâneo 10a: Olha, todo o conbecimento é muito importante, ainda mais na fase que ela tá, que é de absorver informação, cultura... quanto mais cultura, melhor. Quanto mais absorção da cultura, qualquer cultura, é legal, porque a pessoa vai se tornando um adulto melhor, mais inteligente, com mais capacidade de se conhecer e conbecer melhor tudo. [grifos nossos]

Alguns dos que relataram não ter costume de fazer programas culturais, como é o caso do visitante Espontâneo 10a, demonstraram preocupação e vontade de se inserir mais no meio cultural. Para estes, o acesso a esse universo era algo novo, recente, e considerado uma oportunidade importante de inserção social e cultural. Apesar de não terem abordado tanto a questão econômica, alguns depoimentos deixaram claro que a cobrança de ingresso em alguns espaços culturais era um fator limitador de participação e inclusão na agenda cultural local.

Sobre a relação dos entrevistados com o Museu Ciência e Vida em particular, identificamos diferentes tipos de envolvimento com a instituição. Alguns estavam visitando o espaço pela primeira vez e outros eram frequentadores assíduos. Chamou-nos atenção o fato de alguns destes visitantes morarem em Duque de Caxias e não conhecerem o museu - alguns dos entrevistados reivindicaram maior divulgação do museu e de suas atividades para a população. Sobretudo aqueles que elogiaram o espaço insistiram que era preciso que as pessoas soubessem de sua existência, ressaltando o fato de que, por ser gratuito e bem localizado, todos teriam acesso fácil ao museu. Dos entrevistados, apenas uma visitante e o grupo de adolescentes tinham ido ao museu especificamente para participar da visita teatralizada. A primeira viu uma chamada para a atividade no Facebook do museu e as últimas se informaram através do site da instituição.

\section{Recepção da atividade}

Embora a visita teatralizada tenha seguido o mesmo roteiro em todas as apresentações, os visitantes consultados a receberam de formas diversas, expressando diferentes opiniões sobre a atividade e diferentes motivos para terem gostado ou não dela. Em apenas duas das dez entrevistas os visitantes apresentaram visões negativas sobre a visita. No outro extremo, apenas três falaram de forma entusiasmada sobre a mesma, demonstrando um nível de apreciação maior do que os demais.

Um dos aspectos mais apreciados da visita foi a interatividade da atividade, sobretudo as partes em que o ator estimulava a participação do público. Para alguns dos visitantes, a exemplo do que mostra o depoimento a seguir, a interatividade é uma forma interessante e prazerosa de se trabalhar os conteúdos propostos:

Espontâneo 4b: ... essa pecinha que teve agora, esse teatrinho, foi muito interativo, en gostei, porque é a forma de você entender melhor, né? O que está sendo passado, é, é... o que está exposto, é muito melhor. [grifos nossos] 
A performance do ator também foi elogiada pelos visitantes, por ter conseguido fazer o espectador "entrar dentro da história", "empolgar" e "prender a atenção" de quem estava participando, especialmente das crianças.

Curiosamente, um dos pontos negativos destacados pelos visitantes foi justamente a falta de interatividade na visita teatralizada. Um pai que levou o filho e o sobrinho fez críticas contundentes neste sentido, afirmando que a apresentação fora pouco interativa e muito textual, cansativa e inadequada para crianças daquela idade (no caso, de 8 e de 11 anos).

\section{Entrevistadora: Para esse foi mais fácil entender...? \\ Espontâneo 3: Pra ele, ele achou chato porque ele achou muito textual. \\ Entrevistadora: Entendi. \\ Espontâneo 3: E o outro não entendeu nada. \\ Entrevistadora: ... Mas essa atividade você recomendaria pra alguém? \\ Espontâneo 3: Essa daqui? Só se fosse para uma criança acima de 11 anos.}

A inadequação do formato e conteúdo da visita para crianças foi um aspecto destacado mesmo por visitantes que gostaram da atividade. A visitante Espontânea 6, por exemplo, achou a apresentação "bonita", mas inadequada ao filho de cinco anos:

Espontânea 6: Eu achei legal, bonito. Mas ele não prestou muita atenção, eu acho que é pra criança maior, né? Porque tem que ficar sentado, quietinho e ele não ficou muito, então eu acho que não é pra idade dele, mas foi bonito.

Um grupo criticou particularmente a falta de elementos teatrais na atividade. Suas integrantes esperavam ver a encenação de uma peça nos moldes tradicionais, com cenário, atores com figurino e outros elementos cênicos. Esperavam ainda que a atividade tratasse de questões ambientais e envolvesse atos heroicos. Este grupo foi um dos que foram ao museu especificamente para a visita teatralizada, após se informar sobre ela no site do museu, que convidava os visitantes a participar de "apresentações lúdicas com enfoque ecológico em torno da obra de Antoine de Saint Exupéry” na exposição 'A herança da Terra: salvar o planeta do Pequeno Príncipe’. O fato de a atividade abranger aspectos diferentes do esperado acabou confundindo as visitantes e causando frustração.

Espontâneo 5a: Salvar o planeta do Pequeno Príncipe... eu não entendi. Pra mim, salvar o planeta é heroísmo, salvar o planeta, como combater o mal, combater as... o povo que corta as árvores, tudo, que joga lixo no chão, assim. Mas não, ele comecou a falar da França, a minha mãe... eu: o quê? Ele tá salvando o quê?

Apesar de a maioria ter declarado que gostou da visita, poucos foram capazes de apontar partes da apresentação que tivessem sido marcantes ou provocado diferentes reações e emoções. Quando destacavam ou deixavam transparecer ter se emocionado com algum trecho da visita, observamos que esses relatos eram bastante pessoais e tratavam mais da experiência individual do visitante do que da visita propriamente dita. 
Exemplo disso é o relato da visitante Espontânea 1a, que disse ter se emocionado com a apresentação. Ela contou que a visita a remeteu à infância, quando assistia ao desenho do Pequeno Príncipe. Isso a fez resgatar várias lembranças e reviver momentos do passado. Durante a conversa, ela "deixa escapar" que teve uma infância sofrida, que perdeu a mãe cedo e que o Pequeno Príncipe foi uma espécie de escape da dura realidade:

Espontâneo 1a: [...] Porque, assim, a minha infância foi uma infância meio sofrida. Perdi minha mãe aos oito anos. Então como é que era? Eu vivia no meio de adultos. Eu tenho dę irmãos mais velhos do que eu, meu pai. Então a minha infância era praticamente ver televisão, ir para a escola e ficar com os amigos. E o Pequeno Principe foi um tipo de autoajuda para mim, entendeu? Era uma criança solitária, em um planeta sozinho, e eu criança tinha perdido minha mãe e também praticamente tava sozinha. Ai eu ficava assim, como que nesse planeta ele consegue viver? O que que come? O que que ele bebe? Onde ele dorme?

Outro exemplo é o relato do visitante Espontâneo 10a, que disse ter se sensibilizado com a imagem aérea de uma cidade cheia de tanques de guerra, que fazia parte da exposição. Ao mesmo tempo em que achou a imagem bonita, ela o fez refletir sobre violência:

Espontâneo 10a: França... toda verde e tem um painel dos tanques de guerra, como destrói. É um negócio que ficou belo de cima, assim, os tanques destruídos, e ao mesmo tempo fiquei perplexo de tanta violência que tem.

Em um momento mais avançado da conversa, o mesmo visitante falou sobre o contexto da violência em Duque de Caxias, algo que parece o incomodar e preocupar.

Espontâneo 10a: Eu acho que, quanto mais divulgar, melhor. Ainda mais que a gente vive numa cidade que reina a violência, aqui nesse município, infelizmente, a tendência da nossa cultura é ficar baixa. As pessoas querem muita farra, muito tudo, esquecem a cultura. Quanto mais levar isso para escola, acho que melhor.

É possível que a imagem dos tanques de guerra tenha chamado sua atenção justamente por esse contexto e pela preocupação que tem de criar sua filha em uma região marcada pela violência.

A visita também foi capaz de despertar em alguns a curiosidade pela história do Pequeno Príncipe e vontade de ler o livro, como foi o caso dos integrantes do segundo grupo entrevistado:

Espontâneo 2a: Ah, eu achei muito interessante. Inclusive eu tenbo até o livro em casa, mas a gente ainda não leu.

Entrevistadora: Você tem o livro em casa?

Espontâneo 2a: Tenho, mas a gente ainda não teve e a oportunidade de ler. Eu achei muito interessante. [...]

Espontâneo 2c: Eu concordo... pra gente, o que ele explicou, ele leu o livro, ele explicou... Espontâneo 2a: Deu curiosidade de ler o livro. 
Espontâneo 2c:... explicon o livro de uma maneira assim que deixou aquela curiosidade, de você falar assim, poxa, vou sair daqui e já vou atrás do livro. É assim que ele deixou.

Observamos que os entrevistados que declararam ter menos acesso a programas culturais, mas que valorizavam esse tipo de atividade, ficaram mais sensibilizados com a experiência, relatando ter gostado bastante da visita, mesmo sem saber descrever exatamente o que mais lhe agradara. Este foi o caso, por exemplo, da visitante Espontânea 9:

Espontâneo 9: Assim, eu nunca tinha... nunca tinha participado, achei muito interessante. Porque, é... é diferente quando você vê, você tá numa exposição, você tá lendo, você tá... ele praticamente, ele... ai, como é que eu posso... como é que eu posso colocar? É... foi mais intenso. Foi... ele foi colocando, né, com as palavras como se ele fosse o autor. Foi muito, uma experiência muito, muito bacana. Eu gostei muito.

Nesse sentido, cabe registrar que as críticas mais contundentes foram as de um visitante que se declarou frequentador assíduo de museus, tendo levado o filho "mais de cem vezes" (em suas palavras) a esses espaços. O maior acesso a museus e a atividades neles desenvolvidas talvez explique o olhar mais crítico deste visitante em relação à atividade proposta.

\section{Discussão dos resultados}

\section{Perfil dos visitantes e hábitos culturais}

Embora a amostra do presente estudo não represente a totalidade dos visitantes do Museu Ciência e Vida no período analisado, visto que engloba apenas aqueles que participaram das referidas atividades teatrais, identificamos semelhanças entre o perfil sociocultural dos visitantes consultados e o de visitantes de outros 11 museus do Estado do Rio de Janeiro que fizeram parte do estudo do Observatório de Museus e Centros Culturais (OMCC), um programa interinstitucional de produção, compartilhamento e divulgação de dados e conhecimentos sobre os públicos de museus, iniciado em 2003 pelo Museu da Vida, da Fiocruz. Bem como observamos no nosso estudo, dados de 2005 do OMCC indicam que a faixa-etária entre 30 e 39 anos é a que mais visita esses museus, onde a frequência de mulheres também é maior; os visitantes tendem a frequentar museus mais próximos de sua residência; em geral, o fazem acompanhados; e uma parcela importante dos respondentes visitava o museu pela primeira vez (OBSERVATÓRIO DE MUSEUS E CENTROS CULTURAIS, 2006). A similaridade entre os dados apresentados sugere que o perfil dos participantes das atividades teatrais aqui analisadas não difere muito do perfil de frequentadores de outros museus, incluindo de ciências, no Rio de Janeiro. Ou seja, não atraímos necessariamente um público distinto em função das atividades teatrais oferecidas, mesmo porque muitos dos participantes só se informaram sobre tais atividades no próprio museu, o que aponta também para uma falha de comunicação da instituição. Tal falha também se torna evidente quando os visitantes - tanto do Museu Ciência e Vida quanto dos museus avaliados pelo OMCC - apontam a falta de divulgação como principal fator que dificulta a ida a museus. Este é um alerta importante, já que mesmo as instituições 
gratuitas contam com um quadro de visitação aquém de seu potencial. No nosso estudo, vimos que a internet foi uma ferramenta importante para a divulgação de ambas as atividades analisadas. Dado o seu baixo custo e alto retorno, acreditamos que ela poderia ser usada com mais frequência e direcionamento. Mas ainda é preciso pensar em outras estratégias. A dificuldade de transporte também está entre os fatores que limitam a ida a museus para os visitantes de ambos os estudos, um problema de mais difícil solução, pois extrapola a ação individual de cada museu, mas que nem por isso deve ser negligenciado, sobretudo no âmbito do debate sobre as políticas públicas voltadas à cultura no estado e no país.

No que diz respeito ao teatro especificamente, observamos que a ida a espaços teatrais não se configura como um hábito para os visitantes consultados neste estudo. A ausência de teatros perto de casa e questões financeiras foram as principais razões apontadas para a baixa frequência. Cabe destacar que a Baixada Fluminense, região em que se encontra o Museu Ciência e Vida - e de onde a grande maioria dos participantes provém -, é carente em equipamentos culturais tais como museus e teatros. E, diferentemente de muitos museus, que são públicos e gratuitos, a ida ao teatro costuma envolver a compra de ingressos, além de gastos com transporte, um fator que, como vimos, também dificulta a realização de programas culturais. Cabe mencionar que essa falta de hábito de ir ao teatro não se restringe aos visitantes consultados; pelo contrário. Pesquisa sobre os hábitos culturais e as preferências de lazer dos moradores de Duque de Caxias, realizada entre 11 de abril e 30 de maio de 2014, indica que apenas $21 \%$ da população local foi ao teatro ao longo dos 12 meses anteriores à consulta (LEIVA, 2015). Além disso, $33 \%$ jamais haviam estado em um teatro.

Já no que tange às razões para não irem ao teatro, observamos que, embora a falta de estabelecimentos perto de casa e questões financeiras também sejam mencionadas pelos moradores de Caxias na pesquisa supracitada - por $11 \%$ e $22 \%$, respectivamente -, outros motivos revelam-se tão ou mais importantes para não frequentarem esses locais, tais quais a falta de interesse (42\%), a falta de costume (15\%) e a falta de tempo (11\%) (LEIVA, 2015). A pesquisa também mostra que, quanto maior a escolaridade, maior o interesse e mais baixo o percentual de pessoas que dizem nunca ter praticado atividades culturais - incluindo idas a teatros (LEIVA, 2015). Tais dados corroboram diversos outros estudos que apontam a escolaridade como fator de grande influência na realização de programas culturais (ver, por exemplo, BOURDIEU; DARBEL, 2007), inclusive os dados do OMCC. De acordo com Bourdieu (2001a), a escolaridade, a origem social e os valores familiares são determinantes para a aquisição de "capital cultural”, que está fortemente relacionado ao gosto e ao hábito de realizar programas culturais. A falta desse tipo de capital, que extrapola questões puramente econômicas e geográficas e que caracteriza parcela significativa da população brasileira é um desafio para a divulgação científica. Embora haja um discurso crescente de democratização e acessibilidade ao conhecimento por meio de iniciativas de popularização da ciência, muitas dessas ações atingem uma parcela já interessada da população, em situação econômica favorecida, com escolaridade alta e capital cultural elevado (ver, por exemplo, CENTRO DE GESTÃO E ESTUDOS ESTRATÉGICOS, 2017; MASSARANI; MOREIRA, 2016; OBSERVATÓRIO DE MUSEUS E CENTROS CULTURAIS, 2006).

Por um lado, os dados deste e de outros estudos evidenciam que a baixa frequência em museus e teatros está associada a um conjunto de fatores complexos, não restritos a questões de divulgação, financeiras, de localização geográfica e de interesse - apesar de todos estes fatores 
serem relevantes de alguma forma. Por outro, reforçam a necessidade e o desafio imposto à educação e à divulgação da ciência de se construir valores, meios e instrumentos para a inclusão de um maior segmento da população em espaços culturais. No caso dos museus de ciência, nos parece cada vez mais claro que, para isso, essas instituições deverão agir em conjunto com as escolas e as famílias.

\section{Recepção das atividades teatrais}

Registramos uma diversidade interessante de percepções sobre a visita teatralizada. Apesar de isso não nos surpreender, não deixa de ser uma forma de mostrar que fatores exteriores à apresentação em si reverberam na forma como os visitantes experienciam a atividade, em consonância com princípios dos estudos culturais de audiência ingleses e os de recepção latino-americanos (MARTIN-BARBERO, 1987; WOLF, 2003).

Verificamos que aqueles que declararam ter menos acesso a programas culturais (menor capital cultural), um envolvimento anterior com o universo do Pequeno Príncipe e cujos filhos presentes demonstraram gostar e se engajar na atividade tenderam a ter uma recepção mais positiva da mesma. Por outro lado, quando a visita não conseguia atrair a atenção da criança do grupo ou a expectativa em relação à atividade era diferente da vivenciada, a tendência foi de insatisfação e frustração. Observamos ainda que aqueles com maior acesso e adesão a programas culturais (maior capital cultural) tenderam a apresentar um olhar mais crítico em relação às atividades.

Os dados indicam também que é importante atentarmos para a relação entre as temáticas das atividades propostas e o público a que se destinam, da mesma forma que Cury (2009) chama atenção para a importância da escolha dos temas a serem musealizados. A autora defende que o discurso expositivo deve ter como referência o cotidiano do visitante. No caso da visita teatralizada, as entrevistas sugerem que a história do Pequeno Príncipe e de seu autor não fazia parte do repertório cultural dos participantes e, portanto, estes raramente reagiram emocionalmente a ela. Tendo em vista que tanto a exposição quanto a visita teatralizada foram concebidas por franceses, sem experiência prévia em museus de ciência brasileiros, talvez tenha faltado o estabelecimento de conexões entre as duas culturas.

Outra questão que pode ser levada em consideração é a preferência do público por gêneros teatrais específicos. A pesquisa sobre os hábitos culturais dos moradores de Duque de Caxias mencionada anteriormente mostra uma preferência forte desse público pela comédia (LEIVA, 2015). Talvez seja o caso, portanto, de investir na produção de atividades teatrais cômicas como uma estratégia inovadora de divulgação científica. Com maior atenção dedicada às preferências culturais locais, propicia-se a construção de um público ainda mais receptivo a atividades teatrais como as estudadas aqui.

Concluímos ainda que atenção especial deve ser direcionada ao público infantil, que teve presença marcante em ambas as atividades teatrais oferecidas e foi o foco central das visitas de grupos familiares, visto que a satisfação das crianças gerou satisfação nos adultos. Mais do que isso, os dados apresentados aqui e observações cotidianas sugerem que, no contexto social em que o museu está inserido, a criança acaba tendo um papel importante no processo de formação educativa e cultural das famílias, visto que, em muitos casos, os pais não provêm de meios familiares nos quais a cultura é valorizada e passam a fazer programas culturais em 
função dos filhos, por achar importante que estes adquiram capital cultural. Na visita teatralizada, especialmente no início, quando há pouca ação e muito texto, verificamos que crianças menores de dez anos tiveram, em geral, dificuldade de reter a atenção na apresentação. Para atividades futuras, deve-se pensar em explorar conteúdos, formatos e linguagens mais adequados a esse público, privilegiando a interatividade, na tentativa de garantir a todos os visitantes uma boa experiência no museu.

\section{O potencial do teatro em museus de ciência}

Como acontece com alguma frequência em outros museus e centros de ciência brasileiros (MOREIRA; MARANDINO, 2015a), as atividades teatrais analisadas neste artigo foram propostas pelo Museu Ciência e Vida para diversificar suas estratégias de divulgação científica e para promover algumas das outras atividades oferecidas pelo museu - uma oficina sobre robótica e uma exposição sobre Antoine de Saint-Exupéry.

Na nossa avaliação, os resultados deste estudo sobre as interações entre ciência e teatro indicam, em consonância com outras pesquisas, algumas supracitadas, que os recursos teatrais têm potencial interessante para a educação e divulgação da ciência em museus. Assim como relatou Richards (2008) sobre as intervenções de atores em exposições no Museu de Ciência de Londres, vimos que as visitas teatralizadas no Museu Ciência e Vida foram capazes, mesmo que em pequena escala, de envolver, emocionar e despertar no visitante o interesse pelo tema abordado - mesmo que um tema relativamente descolado do repertório cultural de seu público-alvo - de uma maneira peculiar, diferente de outras atividades mais tradicionais de popularização da ciência desenvolvidas em museus. Além disso, as atividades teatrais oferecidas foram capazes de atrair um público com poucas opções de lazer cultural, alcançando, dessa forma, um dos principais objetivos da instituição no que diz respeito à democratização da cultura e da arte, em consonância com o que foi observado por Guimarães, Aguilar e Costa (2015) no Museu da Vida, da Fundação Oswaldo Cruz.

Em termos quantitativos, acreditamos que seria possível atrair mais visitantes para atividades similares, o que foi reforçado pelos dados relativos ao interesse declarado de retorno do público consultado. Para isso, vimos também que é necessária uma divulgação mais eficaz dessas atividades e uma comunicação mais profícua entre a instituição e seu público. Em termos qualitativos, é preciso considerar as questões já colocadas sobre as temáticas abordadas e os gêneros explorados, além de dar atenção especial ao público infantil, sempre tendo em mente o contexto, a realidade e o perfil dos visitantes. Para isso, é importante estabelecer um diálogo intenso com os profissionais de teatro responsáveis por conduzir as atividades e interagir diretamente com o público, especialmente quando estes não fizerem parte da equipe permanente do museu, como foi o caso nas atividades aqui analisadas.

\section{Considerações finais}

Com base na análise de duas atividades oferecidas em um museu de ciências, envolvendo recursos teatrais distintos, com objetivos e características diferentes, que geraram, de uma forma geral, reações positivas e boa recepção por parte do público, concluímos defendendo a interação 
entre ciência e teatro como uma estratégia instigante de educação e divulgação da ciência. Os resultados aqui apresentados sugerem que ela é capaz de envolver o público de forma peculiar e invocar nele percepções e emoções que estão relacionadas com sua história de vida, com seus valores e suas experiências cotidianas, destacando-se em relação a estratégias mais tradicionais de educação e divulgação científica.

Por outro lado, verificamos a importância de se compreender melhor diversos aspectos da inserção do teatro no meio da educação e divulgação da ciência, em particular em centros e museus de ciência. Com isso, acreditamos que seja possível explorar, de forma mais eficaz, o potencial dessa arte para o engajamento público no universo científico e a desconstrução de uma visão estereotipada da ciência e do cientista disseminada na nossa sociedade. Além disso, defendemos a relevância de se direcionar esforços para uma melhor compreensão do potencial do teatro com mote científico para a democratização da cultura, em especial entre um público com pouco acesso e/ou interesse por programas culturais como visita a museus e ida a teatros. Teria o "teatro de temática científica" - termo que vem sendo defendido por Moreira e Marandino (2015b) e ao qual nos alinhamos - potencial maior (que outras ações de educação não formal e divulgação de ciência) na aquisição de capital cultural, servindo também como instrumento de inclusão social?

Para responder a estas e outras questões sobre o teatro como estratégia de divulgação científica, necessitamos de avaliações e estudos frequentes e consistentes sobre atividades como essas. Precisamos também conhecer melhor os públicos - no caso, os visitantes de centros e museus de ciência. Só assim poderemos oferecer a eles uma programação e uma experiência museal que reflitam de fato seus interesses e necessidades e, com isso, enriquecer, de forma significativa, seu capital cultural.

\section{Agradecimentos}

Os autores agradecem o apoio do Conselho Nacional de Desenvolvimento Científico e Tecnológico (CNPq).

\section{Referências}

BAUM, L.; HUGHES, C. Ten years of evaluating science theater at the Museum of Science, Boston. Curator: the museum journal, New York, v. 44, n.4, p. 355-369, 2001.

BLACK, D. R.; GOLDOWSKY, A. Science theater as an interpretive technique in a science museum. In: ANNUAL MEETING OF THE NATIONAL ASSOCIATION FOR RESEARCH IN SCIENCE TEACHING, 1999, Boston. Disponível em: < https:/ eric. ed.gov/?id=ED443709>. Acesso em: 27 abr. 2018.

BOURDIEU, P. O capital social: notas provisórias. In: NOGUEIRA, M. A; CATANI, A. (Org.). Escritos de educação. 3. ed. Petrópolis: Vozes, 2001a. p. 65-69.

BOURDIEU, P. Os três estados do capital cultural. In: NOGUEIRA, M. A.; CATANI, A. (Org.). Escritos de educação. 3. ed. Petrópolis: Vozes, 2001b. p. 73-79. 
Almeida, C. S.; Freire, M.; Bento, L.; Jardim, G.; Ramalho, M.; Dahmouche, M.

BOURDIEU, P.; DARBEL, A. O amor pela arte: os museus de arte na Europa e seu público. 2. ed. São Paulo: Edusp, 2007.

CAZELLI, S. Ciência, cultura, museus, jovens e escolas: quais as relações? 2005. $260 \mathrm{f}$. Tese (Doutorado em Educação) - Pontifícia Universidade Católica do Rio de Janeiro, Rio de Janeiro, 2005.

CENTRO DE GESTÃO E ESTUDOS ESTRATÉGICOS. A ciência e a tecnologia no olhar dos brasileiros: percepção pública da C\&T no Brasil: 2015. Brasília: CGEE, 2017. Disponível em: <https://www.cgee.org.br/documents/10195/734063/percepcao_web. pdf $>$. Acesso em: 2 out. 2017.

COHN, S. H. Evaluating the effectiveness of the science museum of Minnesota's traveling theater program. 2010. Thesis (Master of Arts) - University of Minnesota, [Minneapolis], 2010.

CURY, M. X. Uma perspectiva teórica e metodológica para a pesquisa de recepção em museus. In: MARANDINO, M.; ALMEIDA, A. M.; VALENTE, M. E. A. (Ed.). Museu: lugar do público. Rio de Janeiro: Fiocruz, 2009. p. 153-175.

FRUGUGLIETTI, S. The theatre, (art) and science: between amazement and applause! JCOM: journal of science communication, Trieste, v. 8, n. 2, p. 1-3, 2009.

GUIMARÃES, L.; AGUILAR, P.; COSTA, T. Aprendiz de feiticeiro e o duplo papel do teatro em um museu de ciências: a formação de plateia infanto-juvenil com engajamento nas descobertas científicas. In: CONGRESO REDPOP 2015, Medellin. Libro de Memorias... Medellin, 2015. v. 1. p. 1786-1793. Disponível em: <https://www.slideshare.net/ CorporacionParqueExplora/libro-redpop-2015-50527506>. Acesso em: 2 maio 2018.

GUSMÃO, T. et al. O papel do teatro na divulgação da ciência: contando mitos: uma experiência do museu de astronomia e ciências afins. In: SIMPÓSIO NACIONAL DE EDUCAÇÃO EM ASTRONOMIA, 2., 2012, São Paulo. Anais... Disponível em: <https:// www.sab-astro.org.br/wp-content/uploads/2017/03/SNEA2012_TCP48.pdf >. Acesso em: 27 abr. 2018.

HISTÓRIA, CIÊNCIAS, SAÚDE-MANGUINHOS. Rio de Janeiro: Fundação Oswaldo Cruz, v. 13, out. 2006.

HOOPER-GREENHILL, E. Studying visitors. In: MACDONALD, S. (Ed.). A companion to museum studies. Oxford, UK: Blackwell, 2006. p. 362-376.

LEIVA, J. Cultura em Duque de Caxias. 2015. Disponível em: <http://lurdinha.org/site/ wp-content/uploads/habitosculturais_duquedecaxias_jleiva_braskem.pdf $>$. Acesso em: 2 maio 2018.

LOPES, T. Lights, art, science-action! História, Ciências, Saúde-Manguinhos, Rio de Janeiro, v. 12, p. 401-418, 2005.

MARTIN-BARBERO, J. De los medios a las mediaciones: comunicación, cultura y hegemonía. Barcelona: Gustavo Gili, 1987. 
MASSARANI, L.; MOREIRA, I. Science communication in Brazil: a historical review and considerations about the current situation. Anais da Academia Brasileira de Ciências, Rio de Janeiro, v. 88, p. 1577-1595, 2016.

MASSARANI, L.; MOREIRA, I. C.; ALMEIDA, C. Para que um diálogo entre ciência e arte? História, Ciências, Saúde-Manguinhos, Rio de Janeiro, v. 13, n. supl., p. 7-10, 2006.

MEDINA, M.; BRAGA, M. O teatro como ferramenta de aprendizagem da física e de problematização da natureza da ciência. Caderno Brasileiro de Ensino de Física, Florianópolis, v. 27, n. 2, p. 313-333, 2010.

MESSEDER-NETO, H. S.; PINHEIRO, B. C. S.; ROQUE, N. F. Improvisações teatrais no ensino de química: interface entre teatro e ciência na sala de aula. Química Nova na Escola, São Paulo, v. 35, n. 2, p. 100-106, 2013.

MOREIRA, L. M. O teatro em museus e centros de ciência: uma leitura na perspectiva da alfabetização científica. 2013. Tese (Doutorado em Educação) - Universidade de São Paulo, São Paulo, 2013.

MOREIRA, L. M.; MARANDINO, M. O teatro em museus e centros de ciências no Brasil. História, Ciências, Saúde-Manguinhos, Rio de Janeiro, v. 22, n. supl., p. 1735-1748, 2015a. MOREIRA, L. M.; MARANDINO, M. Teatro de temática científica: conceituação, conflitos, papel pedagógico e contexto brasileiro. Ciência \& Educação, Bauru, v. 21, n. 2, p. 511-523, 2015b.

NOGUEIRA, C. M. M.; NOGUEIRA, M. A. A sociologia da educação de Pierre Bourdieu: limites e contribuições. Educação \& Sociedade, Campinas, v. 23, n. 78, p. 15-36, 2002.

OBSERVATÓRIO DE MUSEUS E CENTROS CULTURAIS. I boletim: ano 1: ago. 2006: pesquisa piloto perfil, opinião 2005, onze museus e seus visitantes. Rio de Janeiro, [2006].

Disponível em: < http://www.fiocruz.br/omcc/media/3_boletim_OMCC.pdf>. Acesso em: 2 maio 2018.

RICHARDS, L. Teatro, mediadores, cientistas punk e visitas-guiadas: os altos e baixos da interpretação ao vivo no Science Museum de Londres. In: MASSARANI, L.; ALMEIDA, C. Workshop sul-americano $\&$ escola de mediação em museus e centros de ciência. Rio de Janeiro: Museu da Vida COC Fiocruz, 2008. p. 131-142.

SHEPHERD-BARR, K. Science on stage: from doctor Faustus to Copenhagen. Princeton: Princeton University Press, 2006.

WOLF, M. Teorias da comunicação. 8. ed. Lisboa: Editorial Presença, 2003. 